D

'Paediatric Respiratory Medicine, Nottingham Children's Hospital, Nottingham, UK.

2Paediatric Respirology, National Heart and Lung Institute, Imperial College London, London, UK.

${ }^{3}$ Royal Brompton and Harefield NHS Foundation Trust, London, UK.

\title{
Myths and maxims in paediatric respiratory medicine
}

"Let no-one, ever, ever doubt

What nobody is sure about!"

Hilaire Belloc

The Oxford English dictionary has two broad definitions of a "myth"; one definition alludes to a traditional story and the second one defines it as "a widely held but false belief or idea" with further subcategorisation as "a misrepresentation of the truth" and "an exaggerated or idealised conception of a person or thing". A maxim is defined as "a short, pithy statement expressing a general truth or rule of conduct".

Even with something as fundamental as the symbol used to depict the noble profession of healing there are some myths involved. The caduceus or the staff of Hermes, depicted as a stick entwined by two snakes and surmounted wings is adopted as a symbol, either as an emblem or as part of the logo of hospitals, medical colleges, clinics, professional bodies, prescriptions and medical journals. But SHETTY et al. [1] suggest that this widespread practice is based on a myth and this is a false symbol and has little or nothing to do with the noble art of healing. The true and authentic symbol of medicine is not the caduceus but the Rod of Asclepius. The Rod of Asclepius is a single serpent entwined rod wielded by the Greek god of healing and medicine, Asclepius [1]. Perhaps the greatest exponent of the debunking of myths and misunderstanding was the late, great Dr Richard Asher, who nearly 50 years after his premature death is a "must-read" for us all [2]. A case in point he highlights is the famous Pel-Ebstein fever in Hodgkin's disease, which never actually existed. Pel and Ebstein actually had a patient with Brucellosis. The Hodgkin's myth was copied from textbook to textbook uncritically, occasionally being reinforced by everyone being summoned to see a Hodgkin's patient who by chance had a not dissimilar fever. The slavish copying of the causes of false positive sweat test results from paper to paper is another example of how myths can become embedded [3].

A sound general principle for the young is that the more confidently a proposition is advanced, and the more senior the person advancing it, the more likely it is to be wrong. So we were taught as medical students that the lower airway is sterile, and of course it is not [4]. We inhale thousands of litres of infected, polluted air every day, how on earth could we have ever believed something so fatuous, were it not for excessive deference to seniority.

With regards to medical education and training, myths are misconceptions about prevailing knowledge and its application to education and learning. Myths would have likely originated and been propagated as traditional concepts or practice with no basis in fact or on the knowledge and understanding current at time. A misunderstanding is a mistaken approach or incomplete knowledge that can be resolved with better evidence, while firmly established misunderstandings can become dogma; a point of view put forth as authoritative
Cite as: Bhatt JM, Bush A. Myths and maxims in paediatric respiratory medicine. Breathe 2018; 14: 5-7. 
without basis in fact [5]. These myths could relate to understanding of the disease or be related to what is often thought a "well established" management. However, a lot of medical beliefs range from unproven to untrue and it is suggested that physicians would do well to understand the evidence supporting their medical decision making, and at least recognise when their practice is based on tradition, anecdote or art [6].

There are multiple medical and social myths associated with common diseases like diabetes [7] and asthma [8, 9]. Possible explanations include differences in the training background and professional vocabulary of education [10], or could relate to extrapolation of similar clinical issues encountered in adult medicine, for example, gastrooesophageal reflux and asthma or that paediatric bronchiectasis is irreversible. Many of these are myths that have long been dispelled and even forgotten, while others are controversial. Whatever the origins of these myths, they may be quite pervasive among students, trainees and trainers. A search of PubMed for articles with "myth" in the title and filters of publication in the last 5 years and in the English language returns 504 results! When further filtered by adding the term children to the search, the top three topics relate to asthma, food allergy and vaccinations. It has been recognised and often quoted in medical education and training that "Half of what you are taught as medical students will in 10 years have been shown to be wrong" [11]. With rapid and ever advancing research, it is without question that in the future, many things taken as either fact or "clinical experience" today will be proven wrong and the "myth" dispelled [5].

However, even solid evidence may not be enough to overturn the most entrenched myths. Grigg and co-workers carried out two randomised controlled trials of nearly 1000 patients $[12,13]$ which showed that prednisolone was totally useless as treatment for an attack of wheeze in the pre-school years. Yet still these medications are dispensed in this context, and there are still calls for new randomised controlled trials [14], despite data from some of the biggest and best trials undertaken in pre-school children in paediatric pulmonology!

The discussion about adherence to these myths is not just of academic interest, it can result in under- or over-diagnosis and/or under- or overtreatment of common conditions like asthma. Some of the most common myths regarding asthma diagnosis and treatment have been well discussed in lay [9] and medical [8] literature, but there is recognition for "transformational thinking" about asthma [15] and it behoves the paediatric respiratory community to constantly challenge and examine the "myths" (e.g. all asthma is the same) and establish new maxims (e.g. have "zero tolerance for attacks") associated with airways disease as proposed by the recent Lancet commissions [16].

Similar discussions have also been documented for cystic fibrosis [5], bronchopulmonary dysplasia [17] and primary ciliary dyskinesia (PCD) [18]. Multicentre collaborative research efforts, that allowed larger numbers of patients to be studied together, have dispelled the myth that PCD is a benign disease associated with a normal lifespan and identified that there is a wide spectrum of severity of lung disease in PCD, from relatively normal lung function associated with a normal lifespan to progressive widespread bronchiectasis with the need for lung transplantation in early adulthood. Rather than being a benign disease, it has been shown that PCD patients of all ages suffer a significant burden of disease symptoms and decreased quality of life. The "realities" associated with PCD were also documented. For example, diagnostic testing for PCD is difficult to access: this is often the origin of one of the common frustrations of many patients with PCD in that they have often consulted with multiple physicians before the diagnosis is finally made in a tertiary care centre with expertise in the diagnosis of PCD.

Over the next few issues of Breathe, we aim to explore a number of myths and maxims related to some common and less common conditions clinicians in paediatric respiratory medicine encounter on a regular basis. The aim is to be provocative and anarchic, and we also want to hear from (preferably junior) paediatric pulmonologists who want to commence a mass migration of sacred cows to the abattoir. We will be soliciting articles from paediatric pulmonologists (in training and trained) to contribute to a discussion on myths and maxims in paediatric respiratory medicine. Generating this sort of discussion is only a start in dispelling common myths as it is well recognised that doctors (other of course than the authors!) are not excluded from being wired to cling stubbornly to their beliefs and facts may not be enough to change minds about health myths [19].

\section{Conflict of interest}

None declared.

\section{References}

1. Shetty A, Shetty S, Dsouza O. Medical symbols in practice: myths vs reality. J Clin Diagn Res 2014; 8: PC12- PC14.
2. Asher R, Jones FA. Richard Asher talking sense: a collection of papers, including the triad 'Sense and sensibility', 
'Myxoedematous madness', 'The dangers of going to bed', and 'Munchausen's syndrome'. London, Pitman, 1982.

3. Casaulta C, Stirnimann A, Schoeni MH, et al. Sweat test in patients with glucose-6-phosphate-1-dehydrogenase deficiency. Arch Dis Child 2008; 93: 878-879.

4. Hilty $M$, Burke $C$, Pedro $\mathrm{H}$, et al. Disordered microbia communities in asthmatic airways. PLoS One 2010; 5: e8578.

5. Rubin BK. Cystic fibrosis: myths, mistakes, and dogma. Paediatr Respir Rev 2014; 15: 113-116.

6. Vreeman RC, Carroll AE. Medical myths. BMJ 2007; 335: 1288-1289.

7. Kanungo A. Myths about type 1 diabetes: awareness and education. Indian J Endocrinol Metab 2015; 19: Suppl. 1 , S24-S25.

8. Rubin BK. Asthma myths, controversies, and dogma. Paediatr Respir Rev 2015; 16: 83-87.

9. Bottrell J. 12 Asthma Myths Worth Noting. https://asthma.net/ living/10-myths-worth-noting/ Date last updated: December 8, 2016.

10. Macdonald K, Germine L, Anderson A, et al. Dispelling the myth: training in education or neuroscience decreases but does not eliminate beliefs in neuromyths. Front Psycho/ 2017; 8: 1314.

11. Pickering GW. The purpose of medical education. $\mathrm{Br}$ Med J 1956; 2: 113-116.
12. Oommen A, Lambert PC, Grigg J. Efficacy of a short course of parent-initiated oral prednisolone for viral wheeze in children aged 1-5 years: randomised controlled trial. Lancet 2003; 362: 1433-1438.

13. Panickar J, Lakhanpaul M, Lambert PC, et al. Oral prednisolone for preschool children with acute virus-induced wheezing. N EnglJ Med 2009; 360: 329-338.

14. Beigelman A, King TS, Mauger D, et al. Do oral corticosteroids reduce the severity of acute lower respiratory tract illnesses in preschool children with recurrent wheezing? J Allergy Clin Immunol 2013; 131: 1518-1525.

15. Camargo CA. Transformational thinking about asthma. Lancet 2017; in press [https://doi.org/10.1016/ S0140-6736(17)32126-8]

16. Pavord ID, Beasley R, Agusti A, et al. After asthma: redefining airways diseases. Lancet 2017; in press [https:// doi.org/10.1016/S0140-6736(17)30879-6].

17. Donn SM. Bronchopulmonary dysplasia: myths of pharmacologic management. Semin Fetal Neonatal Med 2017; 22: 354-358

18. Dell SD. Primary ciliary dyskinesia: myths and realities. Paediatr Child Health 2008; 13: 668-670.

19. Collier R. Facts not enough to change minds about health myths. CMAJ 2017; 189: E1430. 